\title{
Vasikoiden fysikaaliset ympäristöolosuhteet lypsykarjapihatoissa
}

\author{
Milla Ohtonen $^{1)^{*}}$, Suvi Pekkanen ${ }^{2)}$, Risto Kauppinen ${ }^{2)}$, Anne Pentikäinen ${ }^{2)}$, Henna Niskanen ${ }^{2)}$, Jaakko \\ Mononen ${ }^{1)}$, Leena Ahola $^{1)}$, Kristiina Dregde ${ }^{3)}$, Veikko Tuovinen ${ }^{2)}$, Arto Huuskonen ${ }^{4}$ ja Leena \\ Tuomisto ${ }^{4}$ \\ ${ }^{1)}$ Kuopion yliopisto, Soveltavan biotekniikan instituutti, PL 1627, 70211 Kuopio, \\ etunimi.sukunimi@uku.fi,*mohtonen@hytti.uku.fi \\ ${ }^{2)}$ Savonia-ammattikorkeakoulu, PL 72, 74101 Iisalmi, etunimi.sukunimi@savonia-amk.fi \\ ${ }^{3)}$ Helsingin yliopisto, Eläinlääketieteellinen tiedekunta, Saaren yksikkö, Pohjoinen pikatie 800, 04920 \\ Saarentaus,etunimi.sukunimi@helsinki.fi \\ ${ }^{4)}$ MTT/Pohjois-Pohjanmaan tutkimusasema,92400 Ruukki,etunimi.sukunimi@mtt.fi
}

\section{Tiivistelmä}

Vasikoiden kasvatusympäristön tulisi tarjota vasikoille sellaiset olosuhteet, että ne tukevat vasikoiden hyvinvointia ja luovat edellytykset hyvälle kasvulle ja terveydelle. Kasvatusolosuhteissa on tilakohtaisia eroja. Tässä tutkimuksessa selvitettiin vasikoiden fysikaalisia kasvatusolosuhteita lypsykarjapihatoissa. Mittaukset suoritettiin talvella ja kesällä 2005.

Tutkimus toteutettiin 19 lypsykarjatilalla, joissa oli lämminpihatto (keskimäärin 40 - 60 lehmää). Tutkimuksessa selvitettiin vasikoiden kasvatusympäristön ilman lämpötila, -kosteus, -liike, hiilidioksidi- ja ammoniakkipitoisuus, valaistus ja melutaso sekä vasikoiden kasvatustilojen mitoitus ja käytetyt karsinamateriaalit.

Tutkimukseen osallistuneista tiloista erillinen vasikkaosasto omine ilmanvaihtoineen oli vain muutamalla tilalla. Talvi- ja kesäolosuhteissa suoritettujen mittausten välillä suurimmat erot havaittiin ilman lämpötilassa, -kosteudessa, -liikkeessä sekä kaasupitoisuuksissa. Talvella vasikkaosaston lämpötila jäi alle suositellun $15^{\circ} \mathrm{C}$ :n kaikilla tiloilla. Vetoisuus ei aiheuttanut erityisiä ongelmia, mutta ammoniakkipitoisuudet olivat melko korkeita sekä vasikka- että lehmäosastoissa. Kesämittauksissa vasikkaosaston suhteellinen ilmankosteus jäi alle suositellun $60 \%$ :n yli puolella tutkimustiloista.

Valaistus oli erittäin hyvä kaikilla tutkimukseen osallistuneilla tiloilla. Melutasot olivat suositusten ylärajoilla etenkin lehmien osastossa. Huomattavin yksittäinen melunaiheuttaja on ilmastointi.

Tilaa vasikkaa kohden oli keskimäärin $3 \mathrm{~m}^{2}$, ryhmäkoko vaihteli välillä 2 - 11 vasikkaa/karsina. Siirto ryhmäkarsinaan tapahtui yleensä 1 - 3 vuorokauden kuluttua syntymän jälkeen. Karsinarakenteet olivat puuta ja teräsputkea, kuivitukseen käytettiin purua, olkea ja turvetta.

Tutkimukseen osallistuneilla tiloilla vasikoiden fysikaaliset ympäristötekijät ovat yleensä Maaja metsätalousministeriön säännösten ja suositusten mukaisia. Vasikoiden hyvinvoinnin kannalta huomiota tulisi kiinnittää vasikkaosaston alhaiseen lämpötilaan talvella sekä korkeahkoihin melutasoihin ja kaasupitoisuuksiin.

Asiasanat: vasikat, ympäristö, mittaukset, lämpötila, kaasut, pihatot 


\section{Johdanto}

Useilla fysikaalisilla ympäristötekijöillä on vaikutusta eläinten hyvinvointiin ja terveyteen ja sitä kautta kasvuun ja rehun hyväksikäyttöön. Näistä tärkeimpiä ovat lämpötila, ilman nopeus, ilman kosteus ja laatu, valo ja melu sekä eläimen tilantarve (Valros 2005). Vasikoiden kasvatusympäristön tulisi tarjota vasikoille sellaiset olosuhteet, että ne tukevat eläinten hyvinvointia ja luovat edellytykset vasikan kehittymiselle kestäväksi ja kannattavaksi tuotantoeläimeksi.

Lämpötila on yksi merkittävimmistä eläimen hyvinvointiin vaikuttavista ympäristötekijöistä. Kaikilla eläimillä on optimaalinen lämpötila-alue, jossa se viihtyy ja kokee olonsa miellyttäväksi. Tällöin eläimen on helppo ylläpitää normaali ruumiinlämpö (Kinanen ym. 1983). Vasikat ovat herkempiä kylmälle kuin aikuiset naudat. Tämä johtuu suuresta ruumiin pinta-alasta suhteessa painoon, ohuesta nahasta, vähäisestä rasvakudoksen määrästä ja heikosta ääreisverenkierron säätelystä (Myllys 1999). Vasikkaosaston optimilämpötilaan vaikuttavat mm. vasikan ikä, makuupaikka ja kuivitus sekä vetoisuus. Lämpötila tulisi pyrkiä pitämään tasaisena, sillä vaihtelut altistavat erilaisille tulehdussairauksille (Aho 2002). Vastasyntyneillä vasikoilla optimaalinen lämpötila on $15-22{ }^{\circ} \mathrm{C}$ astetta (Rajala, H. 1993).

Navettatilan optimaalinen ilmankosteus on noin 60 - $80 \%$ suhteellista kosteutta (Rajala, H. 1993). Riittävän korkea ilmankosteus on välttämätön pitämään eläinten hengitystiet hyvässä kunnossa. Jos pysyvä suhteellinen ilmankosteus ylittää $85 \%$, voi se aiheuttaa navettarakenteiden vaurioitumista ja vaikeuttaa navetan ja eläinten puhtaanapitoa (Myllys 1999; Navetan ilmanvaihto 2003).

Ilman liike lisää lämmönhukkaa. Ilman liike saisi olla korkeintaan $0,1-0,2 \mathrm{~m} / \mathrm{s}$. Vetoisuus altistaa vasikat keuhko- ja niveltulehduksille varsinkin kylmässä lämpötilassa. Kesällä korkeammassa lämpötilassa ilman nopeus ei saisi ylittää $0,5 \mathrm{~m} / \mathrm{s}$ (Kinanen ym. 1983).

Navetan huono sisäilma aiheuttaa eläimelle stressiä, altistaa sairauksille sekä heikentää vastustuskykyä ja tuottavuutta. Ilmanvaihdon tehtävänä on poistaa navettailmasta $\mathrm{mm}$. ilmanlaatua heikentävä pöly ja mikro-organismit sekä haitalliset kaasut, kuten hiilidioksidi, ammoniakki, , metaani, ja rikkivety (Rajala, P. 1990). Pitkäaikainen altistuminen korkeille ammoniakkipitoisuuksille vaikuttaa eläimen yleiskuntoon ja voi aiheuttaa hengityselinten sairauksia sekä silmien ja suun limakalvovaurioita. Ammoniakkipitoisuus ei saisi ylittää $10 \mathrm{ppm}$ rajaa. Hiilidioksidille vastaava rajaarvo on $3000 \mathrm{ppm}$. (Ewing ym. 1999). Korkea hiilidioksidipitoisuus voi aiheuttaa hapenpuutteen tunnetta ja nopeuttaa hengitystiheyttä.

Melulla tarkoitetaan tarpeettoman kovaa tai haitallista ääntä. Melun intensiteettiä mitataan desibeleinä $(\mathrm{dB})$. Naudan kuuloalue on laaja ja kuuloherkkyys korkeita taajuuksia lukuun ottamatta jopa parempi kuin koiralla (Heffner \& Heffner 1983). Tavallisimpia melunlähteitä navetassa ovat eläimet itse, parsikalusteet sekä ilmastointi- ja ruuanjakolaitteet. Korkea melutaso aiheuttaa eläimille stressiä ja voi siten altistaa metabolisille ja infektiivisille sairauksille (Hillman ref. Rajala, P. 1990). Maa- ja metsätalousministeriön suosituksen mukaan naudat eivät saa jatkuvasti altistua yli 65 desibelin melulle.

Valaistuksella on todettu olevan vaikutusta nautojen lisääntymiseen, kasvuun ja maitotuotokseen. (Peters ref. Frandson \& Spurgeon 1992). Karjasuojien valaistuksen tulee olla naudalle sopiva ja riittävä eläinten asianmukaiseen tarkastamiseen ja hoitamiseen. Yleisvalaistuksen voimakkuudeksi suositellaan noin 100 luksia (Maa- ja metsätalousministeriö 2003).

Vasikan tilantarve kasvaa eläimen kasvaessa. Alle $150 \mathrm{~kg}: \mathrm{n}$ painoista vasikkaa kohti tilaa on oltava vähintään $1,5 \mathrm{~m}^{2}$, yli $220 \mathrm{~kg}$ painavalla $1,8 \mathrm{~m}^{2}$. Sekä yksittäis- että ryhmäkarsinassa vasikalla on oltava riittävästi tilaa kääntyä ympäri ja asettua vaivatta makuulle (Maa- ja metsätalousministeriö 2003). Yksittäiskarsinassa vasikkaa voidaan pitää 8 viikon ikään saakka. Tällöinkin eläimellä tulisi olla mahdollisuus nähdä ja kosketella lajitovereitaan. Karsinan makuualueen on oltava aina kiinteä ja mieluiten hyvin kuivitettu (Castrén 1997 ).

Tässä tutkimuksessa selvitettiin vasikoiden kasvatusolosuhteita lypsykarjapihatoissa ja pyrittiin löytämään vasikoiden kannalta hyvin toimivat rakenneratkaisut. Tutkimus suoritettiin osana Lypsykarjarakennusten toiminnalliset mitoitusvaihtoehdot tutkimuskokonaisuutta (MTT/Maa-ja elintarviketalouden tutkimuskeskus) ja ELKE 1 -hanketta (Eläinterveydenhuollon kehittämishanke Pohjois-Savossa). 


\section{Aineisto ja menetelmät}

Tutkimus toteutettiin 19 lypsykarjatilalla, joissa oli lämminpihatto (keskimäärin 40 - 60 lehmää). Mittaukset tehtiin talvella ja kesällä 2005. Mittauksissa selvitettiin vasikoiden kasvatusympäristön ilman lämpötila, ilmankosteus, ilman liike, ilman hiilidioksidi- ja ammoniakkipitoisuus, valaistus ja melutaso sekä vasikoiden kasvatustilojen mitoitus ja materiaalit. Vertailun vuoksi samat mittaukset suoritettiin myös lehmien osastossa.

Ilman lämpötila ja suhteellinen ilmankosteus rekisteröitiin 15 minuutin välein vuorokauden ajan loggereilla (Escort Junior EJ-HS-B-4). Loggeri asetettiin vasikoiden osastoon $80 \mathrm{~cm}$ korkeudelle lattiatasosta. Lehmien osastoon asetettiin vastaavalla tavalla lämpötilaa rekisteröivä loggeri.

Ilmanvirtaus ja ilman hetkellinen lämpötila mitattiin sekä vasikkakarsinassa että lehmäosastossa kuudesta eri pisteestä $10 \mathrm{~cm}$ ja $80 \mathrm{~cm}$ korkeudelta lattiatasosta monitoimimittarilla (Velocicalc Plus, mittausalue $0-50 \mathrm{~m} / \mathrm{s}$ ).

Hiilidioksidi- ja ammoniakkipitoisuutta mitattiin diffuusioputkilla (Dräger Röhrchen; ammonia 20/a-D, carbon dioxide 500/a-D). Putket sijoitettiin loggereiden välittömään läheisyyteen, etäälle ilmanvaihtoaukoista. Mittausaika oli kaksi tuntia. Tulos luettiin värimuutoksen perusteella putken asteikolta ja suhteutettiin mittausaikaan.

Valaistusta mitattiin karsinasta lux-mittarilla (Roline TES-1335, mittausalue 0,01 - 400000 lx) hetkellisesti kuudesta eri pisteestä karsinoiden reunalta ja keskeltä. Lehmien osastossa vastaavat mittaukset tehtiin makuuparsissa ja käytävillä.

Melutasoa mitattiin desibelimittarilla (Roline RO-1350, mittausalue 35 - $130 \mathrm{~dB}$ ) kahdeksasta mittauspisteestä, joista kaksi sijaitsi ruokintapöydällä ja kuusi vasikoiden karsinassa/lehmäosastossa.

Lisäksi selvitettiin vasikoiden ikä ryhmäkarsinaan siirrettäessä, vasikoiden lukumäärä/karsina ja mitattiin mittanauhan avulla karsinoiden pinta-ala.

\section{Tulokset ja tulosten tarkastelu}

Tutkimukseen osallistuneista tiloista vain neljällä oli erillinen vasikkaosasto omine ilmanvaihtoineen. Useimmilla tiloilla vasikkaosasto sijaitsi hieman sivussa lehmien osastosta, mutta kuitenkin välittömässä näköyhteydessä. Yleinen ratkaisu navettalaajennuksen tehneillä tiloilla oli sijoittaa vasikat ja nuorkarja vanhan navetan muodostamaan 'siipirakennukseen' lehmäosaston sijaitessa uudessa osassa.

Talvella vasikkaosaston lämpötila jäi alle suositellun $15{ }^{\circ} \mathrm{C}: n$ kaikilla tutkimukseen osallistuneilla tiloilla. Alhaisin yksittäinen talviolosuhteissa vasikkaosastosta mitattu lämpötila oli 4.1 ${ }^{\circ} \mathrm{C}$ ja korkein $15.2^{\circ} \mathrm{C}$. Kesällä vastaavat lämpötilat olivat $10.2^{\circ} \mathrm{C}$ ja $26.9^{\circ} \mathrm{C}$. Lehmien osastossa talviolosuhteissa matalin mitattu lämpötila oli $0.8{ }^{\circ} \mathrm{C}$ ja korkein $23.0{ }^{\circ} \mathrm{C}$, kesäolosuhteissa $12.1^{\circ} \mathrm{C}$ ja $26.2{ }^{\circ} \mathrm{C}$. Ulkolämpötila vaikuttaa navetan sisälämpötilaan, joten varsinkin talvella tehdyissä mittauksissa kylmän pakkassään vaikutus oli huomattava.

Vasikkaosaston suhteellinen ilmankosteus oli talvimittauksissa suositellun 60 - $80 \%$ :n välillä 11 tilalla, kesäolosuhteissa 12 tilalla arvo jäi alle $60 \%$ :n. Talvimittausten matalin \%RH oli $52.3 \%$ ja korkein $78.95 \%$, kesällä vastaavat arvot olivat $44.46 \%$ ja $66.47 \%$. Lehmien osastosta suhteellista ilmankosteutta ei mitattu.

Vasikkaosastolla ilman nopeus $10 \mathrm{~cm}$ korkeudella lattiatasosta oli talvimittauksissa $0,14 \mathrm{~m} / \mathrm{s} \mathrm{ja}$ kesämittauksissa $0,13 \mathrm{~m} / \mathrm{s}$. Alhaisin mitattu virtaus talvella oli $0,04 \mathrm{~m} / \mathrm{s}$ ja korkein $0,23 \mathrm{~m} / \mathrm{s}$, kesällä vastaavasti $0,07 \mathrm{~m} / \mathrm{s}$ ja $0,22 \mathrm{~m} / \mathrm{s}$. Ilmanvirtaus $80 \mathrm{~cm}$ korkeudella oli $0,10 \mathrm{~m} / \mathrm{s}$ sekä talvi- että kesämittauksissa. Talvimittauksissa ilman nopeus oli alhaisimmillaan $0,08 \mathrm{~m} / \mathrm{s}$ ja korkeimmillaan 0,25 $\mathrm{m} / \mathrm{s}$. Kesällä virtausnopeus oli alhaisimmillaan $0,06 \mathrm{~m} / \mathrm{s}$ ja korkeimmillaan $0,40 \mathrm{~m} / \mathrm{s}$.

Lehmäosastolla ilman nopeus oli suurempi, etenkin kesällä tehdyissä mittauksissa. Tämä aiheutui suureksi osaksi siitä, että lämpimän sään takia ovet ja ikkunat olivat auki. Talvimittauksissa ilman liike $10 \mathrm{~cm}$ korkeudella lattiasta on minimissään $0,10 \mathrm{~m} / \mathrm{s}$ ja maksimissaan $0,31 \mathrm{~m} / \mathrm{s}$. Kesällä samaiset arvot olivat $0,11 \mathrm{~m} / \mathrm{s}$ ja $0,52 \mathrm{~m} / \mathrm{s}$.

Vasikkaosaston matalin mitattu ammoniakkipitoisuus talvella oli 1,00 ppm ja korkein 22,5 ppm. Kesällä matalin ja korkein arvo oli $1,00 \mathrm{ppm}$ ja 10,00 ppm. Lehmäosastossa pitoisuudet olivat suurempia: talvella mitattu minimiarvo oli $5,00 \mathrm{ppm}$ ja maksimi $25,00 \mathrm{ppm}$. Kesällä vastaavat arvot olivat 2,00 ppm ja 15,00 ppm. Minimi- ja maksimihiilidioksidipitoisuudet olivat vasikkaosastossa talvimittauksissa 900 ppm ja 3500 ppm, kesällä 600 ppm ja 2000 ppm. Lehmäosaston 
hiilidioksidipitoisuudet vaihtelivat talvella välillä 1100 ppm - 5000 ppm ja kesällä välillä 500 ppm 2500 ppm.

Valaistus oli riittävä kaikilla tutkimukseen osallistuneilla tiloilla. Vasikkaosastossa mitatut matalimmat ja korkeimmat arvot olivat talvella 39,15 lux ja 681,33 lux, kesällä vastaavat lukemat olivat 47,67 lux ja 1024,17 lux. Lehmäosastossa lukemat vaihtelivat talvella välillä 61,37 lux - 533,67 lux ja kesällä 95,67 lux - 568,33 lux.

Melutasot olivat korkeahkoja sekä vasikka- että lehmäosastossa. Merkittävin yksittäinen melunaiheuttaja oli ilmastointi. Vasikkaosastossa talviolosuhteissa karsinasta mitatut lukemat olivat 43,07 dBA - 68,43 dBA. Ruokintapöydältä mitatut arvot olivat hieman korkeampia; 47,90 dBA 70,30 dBA. Kesällä tehdyissä mittauksissa arvot olivat samankaltaisia: karsinassa 38,72 dBA - 68,17 dBA ja ruokintapöydällä 42,00 dBA - 73,10 dBA. Lehmien osastossa ilmastoinnin lisäksi melua aiheutui rehunjakolaitteista ja parsirakenteista. Talvella mitatut arvot vaihtelivat lehmäosastossa välillä $53,30 \mathrm{dBA}-66,40 \mathrm{dBA}$ ja ruokintapöydällä välillä 52,30 dBA - 68,45 dBA. Kesällä mitatut arvot olivat jonkin verran korkeampia, lehmäosastossa $56,45 \mathrm{dBA}-83,37 \mathrm{dBA}$ ja ruokintapöydällä 57,55 dBA - 69,15 dBA.

Sosiaalisena ja leikkisänä eläimenä vasikka vaatii riittävän ison karsinan. Tutkimukseen osallistuneilla tiloilla tilaa vasikkaa kohden oli keskimäärin $3 \mathrm{~m}^{2}$, minimin ollessa $0,90 \mathrm{~m}^{2}$ ja maksimin $10,65 \mathrm{~m}^{2}$. Ryhmäkoko vaihteli välillä 2 - 11 vasikkaa/karsina. Siirto ryhmäkarsinaan tapahtui tavallisesti 1 - 3 vuorokauden kuluttua syntymästä.

Taulukko 1. Vasikoiden ja lehmien ympäristöolosuhteet lämminpihatossa $(60-80$ lehmää, $n=19)$ talvella ja kesällä 2005.

\begin{tabular}{|lcccc|}
\hline Ympäristötekijä & Vasikat talvi & Vasikat kesä & Lehmät talvi & Lehmät kesä \\
\hline $\begin{array}{l}\text { Ilman lämpötila } \\
\text { vuorokausi- } \\
\text { mittaus, }{ }^{\circ} \mathbf{C}\end{array}$ & $10,63 \pm 2,31$ & $18,15 \pm 2,45$ & $10,88 \pm 3,98$ & $19,41 \pm 2,2$ \\
$\begin{array}{l}\text { Lämpötila 10 cm } \\
\text { lattiatasosta, }\end{array}$ & $11,97 \pm 2,56$ & $19,50 \pm 2,30$ & $11,58 \pm 3,10$ & $20,11 \pm 2,81$ \\
$\begin{array}{l}\text { Lämpötila 80 cm } \\
\text { lattiatasosta, }{ }^{\circ} \text { C }\end{array}$ & $11,85 \pm 2,56$ & $19,43 \pm 2,32$ & $11,56 \pm 3,15$ & $19,80 \pm 3,29$ \\
$\begin{array}{l}\text { Ilmankosteus, } \\
\text { \%RH }\end{array}$ & $64,32 \pm 8,45$ & $55,35 \pm 6,98$ & & \\
$\begin{array}{l}\text { Ilman liike 10 cm } \\
\text { lattiatasosta, m/s }\end{array}$ & $0,14 \pm 0,06$ & $0,13 \pm 0,04$ & $0,21 \pm 0,06$ & $0,22 \pm 0,10$ \\
$\begin{array}{l}\text { Iman liike 80 cm } \\
\text { lattiatasosta, m/s }\end{array}$ & $0,10 \pm 0,05$ & $0,10 \pm 0,05$ & $0,13 \pm 0,40$ & $0,18 \pm 0,09$ \\
$\begin{array}{l}\text { Ammoniakki- } \\
\text { pitoisuus, ppm }\end{array}$ & $10,58 \pm 5,40$ & $5,50 \pm 3,20$ & $13,26 \pm 6,03$ & $7,61 \pm 3,36$ \\
$\begin{array}{l}\text { Hiilidioksidi- } \\
\text { pitoisuus, ppm }\end{array}$ & $1950,00 \pm 709,85$ & $1028,95 \pm 396,27$ & $2607,89 \pm 1068,40$ & $1257,89 \pm 500,35$ \\
$\begin{array}{l}\text { Valaistus, lux } \\
\text { Melu }\end{array}$ & $221,37 \pm 187,87$ & $202,97 \pm 216,05$ & $196,57 \pm 125,58$ & $226,67 \pm 124,79$ \\
$\begin{array}{l}\text { karsina/lehmä- } \\
\text { osasto, dBA } \\
\text { Melu } \\
\text { ruokintapöytä, } \\
\text { dBA }\end{array}$ & $58,44 \pm 7,41$ & $59,62 \pm 5,90$ & $61,12 \pm 3,62$ & $63,98 \pm 5,76$ \\
\hline
\end{tabular}




\section{Johtopäätökset}

Tutkimukseen osallistuneilla tiloilla vasikoiden fysikaaliset ympäristötekijät olivat yleensä Maa- ja metsätalousministeriön säännösten ja suositusten mukaisia. Vasikoiden hyvinvoinnin kannalta huomiota tulisi kiinnittää vasikkaosaston alhaiseen lämpötilaan talvella sekä korkeahkoihin melutasoihin ja kaasupitoisuuksiin. Näihin tekijöihin voitaisiin vaikuttaa rakentamalla erillinen vasikkaosasto. Talvella tulisi olla mahdollisuus lisälämpöön esim. säteilylämmittimien ja lämpölamppujen avulla. Kaasupitoisuuksiin on mahdollista vaikuttaa ilmastoinnilla, runsaalla kuivituksella sekä ilmanpuhdistuslaitteilla. Melun vaikutuksesta nautojen hyvinvointiin tiedetään vielä varsin vähän ja meluntorjunnan tarpeellisuuden selvittäminen edellyttää lisätutkimuksia.

\section{Kirjallisuus}

Aho, P. 2002. Lähiympäristön vaikutus vasikoiden ja lihanautojen hyvinvointiin. Julkaisussa: Yliaho, M. \& Teräväinen, H. (toim.) Nauta- ja sikatilan olosuhdeopas. Tieto tuottamaan 97. Maaseutukeskusten Liiton julkaisuja nro 979, Keuruu: 18.

Castrén, H. 1997. Kotieläinten käyttäytyminen ja hyvinvointi. Helsingin yliopiston Maaseudun tutkimus- ja koulutuskeskus, Mikkeli: 106.

Ewing, S.A., Lay, D.C. \& von Borell, E. 1999. Farm Animal Well-being. Stress Physiology, Animal Behavior, and Environmental Design. Prentice-Hall International (U.K.) Limited, London: 216-217.

Frandson, R.D. \& Spurgeon, T.L. 1992. Anatomy and Physiology of Farm Animals. Fifth Edition. Lippincott Williams \& Wlkins, Phildelphia: 479.

Heffner, R.S. \& Heffner, H.E. 1983. Hearing in Large Mammals: Horse (Equus caballus) and cattle (Bos taurus). Behavioral neuroscience, Vol. 97, 2: 299-309.

Kinanen, M., Markkula, M., Paatela, J., Sallasmaa, S. \& Siitonen, M. 1983. Terve kotieläin. Tieto tuottamaan 25. Maatalouskeskusten Liiton julkaisuja n:o 680, Helsinki: 70-71.

Maa- ja metsätalousministeriö. 2003. Tavoitteena terve ja hyvinvoiva nauta. Elintarvike- ja terveysosaston julkaisuja 1/2003.

Myllys, A. 1999. Naudan hyvä elämä. Helsingin yliopiston Maaseudun tutkimus- ja koulutuskeskus, Mikkeli: 32-37.

Navetan ilmanvaihto. 2003. Teknotiimi. Teknologian siirto 2000-2006 - Maidontuotannosta huipputeknologiaa -hanke. Oulun lääninhallitus, Euroopan sosiaalirahasto ja valtion opetushallinto, Oulu.

Rajala, H. 1993. Nautakarjatalous. Oy West Point, Rauma: 8.

Rajala, P. 1990. Nautakarjan terveydelle merkittävät tuotantoympäristötekijät ja niiden mittaaminen navetassa. Eläinlääketieteellisen korkeakoulun Julkaisuja 7. Peruseläinlääketieteen osasto, Kotieläinhygienia, Helsinki: 1223.

Valros, A. 2005. Hyvinvointi kuvaa eläimen tilannetta kokonaisvaltaisesti. Julkaisussa: Valros, A., Teräväinen, H. \& Helin, J. (toim.) Hyvinvoiva tuotantoeläin. Tieto tuottamaan 109. ProAgria Maaseutukeskusten Liiton julkaisuja nro 1014, Keuruu: 7. 